\title{
Combined surgical and endovascular treatment of complex high-flow conus medullaris arteriovenous fistula associated with Parkes Weber syndrome: case report
}

\author{
Arya N. Bagherpour, DO, ${ }^{1}$ Gustavo J. Rodriguez, MD, ${ }^{2}$ Chetan Moorthy, MD, ${ }^{3}$ Todd T. Trier, MD, ${ }^{4}$ \\ and Alberto Maud, MD²
} Departments of ${ }^{1}$ Radiology, ${ }^{2}$ Neurology, ${ }^{3}$ Pediatric Radiology, and ${ }^{4}$ Neurosurgery, Texas Tech University Health Sciences Center,
El Paso, Texas

Parkes Weber syndrome (PWS) is a congenital overgrowth disorder characterized by unilateral limb and axial hypertrophy, capillary malformations of the skin, and high-flow arteriovenous fistulas (AVFs). Spinal AVFs in the setting of PWS are challenging vascular lesions that often contain multiple arteriovenous (AV) shunts. The present case report highlights an adolescent girl with PWS who presented with a ruptured complex high-flow conus medullaris AVF. She was successfully treated with endovascular embolization and microsurgery. At the 2-year follow-up, the patient remained free of neurological symptoms and had no recurrence of the vascular malformation.

http://thejns.org/doi/abs/10.3171/2016.1.SPINE151156

KEY WORDS Parkes Weber Syndrome; vascular malformation; arteriovenous fistula; treatment; spinal cord; endovascular; vascular disorders

$\mathrm{P}$ ARKES Weber syndrome (PWS) is a rare congenital overgrowth disorder characterized by limb, axial, and visceral hypertrophy; capillary malformations of the skin; and the presence of significant arteriovenous (AV) shunting/high-flow vascular malformations. ${ }^{11,15,16}$ It is a heterogeneous disorder and most often arises sporadically, although familial cases have been described. ${ }^{2} \mathrm{~A}$ genetic link related to a mutation in the RASAl gene has been reported to account for familial PWS. This variant is seen primarily in patients with multiple capillary malformations. ${ }^{10}$

Spinal vascular malformations in the setting of PWS are typically complex, exhibiting multiple AV shunts that demand a multidisciplinary approach because of the unique angioarchitectural characteristics (including the dural and pial feeders in the same lesion). Successful treatment hinges on surgical and/or endovascular interventions to disconnect all fistulous points. We report the case of an adolescent girl with PWS who presented with an acute, nonaneurysmal subarachnoid hemorrhage $(\mathrm{SAH})$ due to a ruptured complex conus medullaris AV fistula (AVF) with multiple AV shunts. She was successfully treated using endovascular embolization and microsurgery.

\section{Case Report}

History and Physical Examination

A 14-year-old girl presented with abrupt-onset severe headache and vomiting, followed by a generalized seizure. CT scanning revealed diffuse $\mathrm{SAH}$, predominantly in the posterior fossa, and mild hydrocephalus. Cerebral angiography demonstrated no intracranial aneurysm. Her prior surgical history included an epiphysiodesis procedure to help prevent progressive lengthening of her hypertrophied left leg. She had also undergone surgical removal of varicose veins and venous malformations in the same limb.

Physical examination revealed left lower-extremity soft-tissue and bony hypertrophy with multiple capillary malformations and hypertrophy of the left breast. Abdominal sonography and MRI demonstrated an asymptomatic left renal AV malformation (AVM). MRI of the spine showed a vascular malformation within the conus medullaris, which was suspicious for an AVM or an AVF, with associated acute hemorrhage within the cord terminus and SAH that extended to the lower lumbar thecal sac (Fig. 1). Spinal angiography revealed a prominent highflow, intradural, ventral AVF fed primarily by the anterior

ABBREVIATIONS AV = arteriovenous; $\mathrm{AVF}=\mathrm{AV}$ fistula; $\mathrm{AVM}=\mathrm{AV}$ malformation; $\mathrm{DSA}=$ digital subtraction angiography; $\mathrm{KTS}=$ Klippel-Trenaunay syndrome; $\mathrm{NBCA}=$ $\mathrm{N}$-butyl cyanoacrylate; PWS = Parkes Weber syndrome; SAH = subarachnoid hemorrhage.

SUBMITTED October 1, 2015. ACCEPTED January 13, 2016.

INCLUDE WHEN CITING Published online March 25, 2016; DOI: 10.3171/2016.1.SPINE151156. 


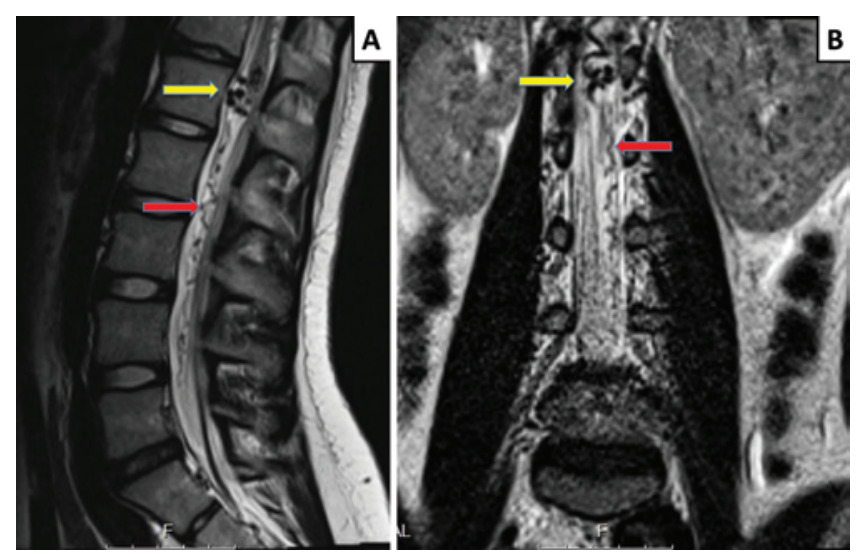

FIG. 1. Sagittal (A) and coronal (B) T2-weighted MR images of the lumbar spine, demonstrating multiple dilated perimedullary veins within the conus medullaris (yellow arrows). A serpiginous draining vein is also seen ascending from the L4-5 level to the conus medullaris (red arrows). Note the markedly enlarged left kidney with multiple dilated flow voids secondary to a renal AVM on the coronal image. Figure is available in color online only.

spinal artery (with a high-flow pial component) arising from the right T-11 intercostal artery (Fig. 2). A second intradural dorsal arterial feeder arising from the posterior spinal artery through the left L-1 lumbar artery was also identified (Fig. 3). The fistula point was located at the transition of the T-12 and L-1 vertebral levels (conus medullaris).

An additional intradural dorsal (slow-flow) AVF arising from the radicular branch of the left L-4 lumbar artery was identified with an ascending serpiginous drain- ing vein up to the fistula point, at the level of the conus medullaris (Fig. 4). There were dilated varicose veins at the fistula point that resembled an intramedullary AV nidus (a pseudonidus angiographic appearance). The fistula finally drained into a long, descending, extradural vein, which then drained into the left common iliac vein. Findings were consistent with the diagnosis of an overgrowth disorder, with phenotypic features of PWS.

\section{Treatment}

During surgery we observed a recent hemorrhage around the spinal cord vascular malformation. The patient underwent bilateral T10-11 laminectomies and surgical ligation of a posterior fistula at the pseudonidus point. Postoperative spinal angiography showed residual filling of the vascular malformation. The patient then underwent endovascular embolization of the right T-11 and left L-1 arterial feeders using $N$-butyl cyanoacrylate (NBCA) and the anterior spinal artery was preserved. Repeat spinal angiography showed persistence of the L-4 intradural dorsal (slow-flow) component, which also required NBCA embolization; this achieved complete cure of the complex fistula (Fig. 5).

\section{Outcome and Follow-Up}

The patient tolerated the surgical and endovascular treatments well, without complications. After 2 years of follow-up, she remained free of neurological symptoms and was cured of the complex AVF.

\section{Discussion}

Our patient's syndrome and presentation are exceedingly rare-spontaneous, nonaneurysmal SAH secondary
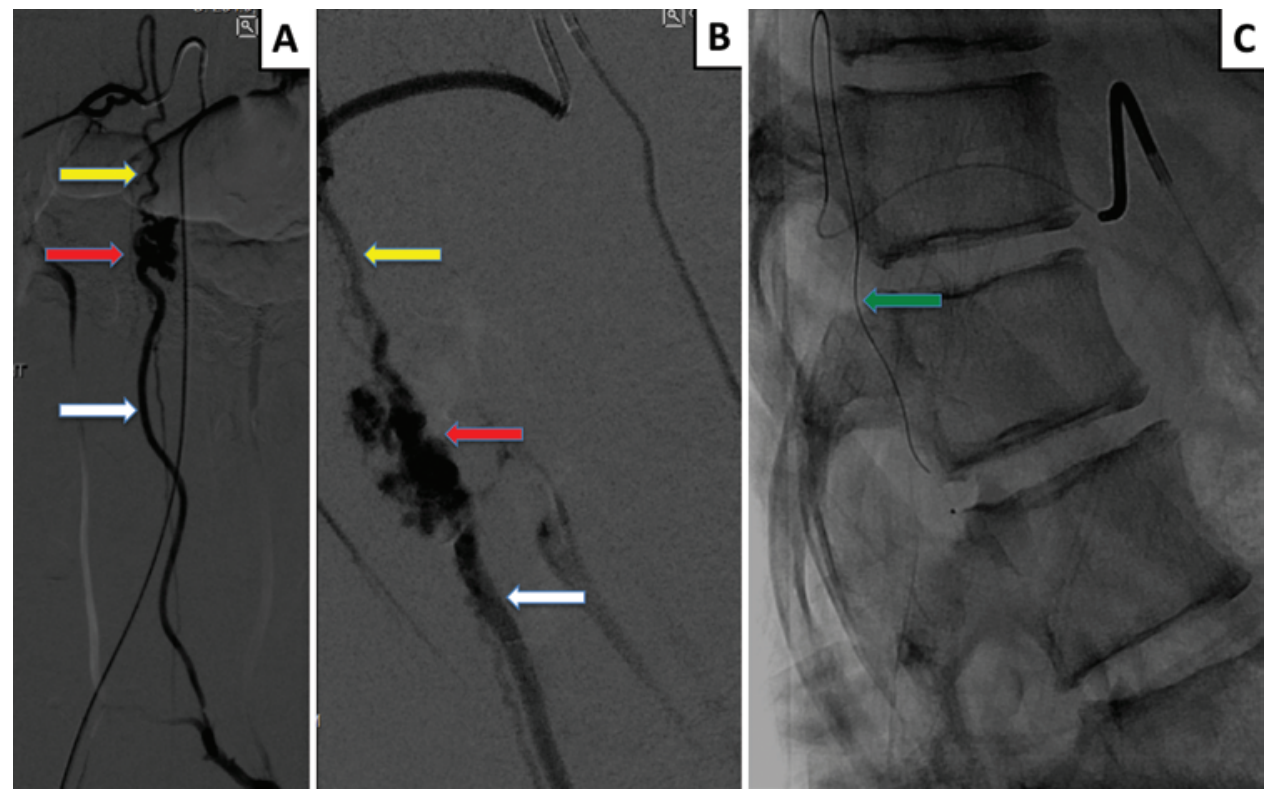

FIG. 2. Anteroposterior (A) and lateral (B) DSA studies of the right T-11 intercostal artery, demonstrating the anterior spinal artery (yellow arrows) feeding the fistula point that has a pseudonidus appearance at the conus medullaris (red arrows) and drains into an arterialized extradural vein (white arrows). Corresponding lateral radiograph (C) with microcatheter within the anterior spinal artery, confirming the ventral location of this intradural fistula (green arrow). Figure is available in color online only. 

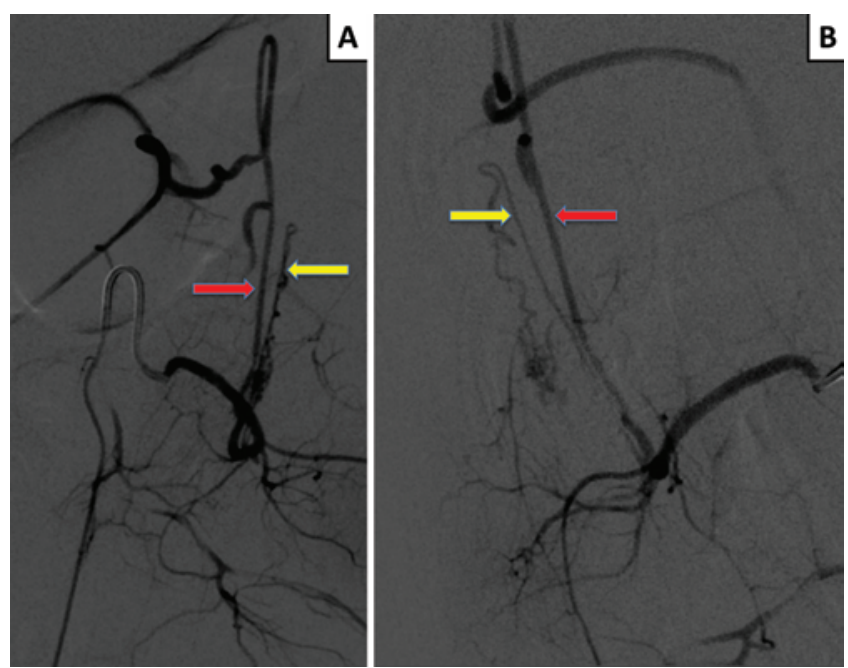

FIG. 3. Anteroposterior (A) and lateral (B) DSA studies showing the intradural dorsal component of the conus medullaris fistula through the left posterior spinal artery (yellow arrows). Note reflux into the anterior spinal artery (red arrows). The anterior and posterior spinal arteries in this image "sandwich" the conus medullaris. Figure is available in color online only.

to a complex, high-flow conus medullaris AVF in the context of PWS. Spinal cord AVFs can be particularly challenging to treat in patients with PWS because the fistula point can have multiple feeders, and multiple fistulas can be present in a single patient.

Our review of the literature found no other cases in which authors describe the unique association of PWS with multiple intraspinal AVFs. There have been, however, 5 case reports in which this condition was characterized as Klippel-Trenaunay-Weber syndrome. Research supports the fact that Klippel-Trenaunay syndrome (KTS) and PWS are in fact 2 independent disorders, and therefore it is inaccurate to group these syndromes together as a single entity.

One case report described a 13-year-old girl who presented with myelopathy and 4 AVFs. ${ }^{7}$ The lesion was successfully treated with platinum fiber coils. Rohany and colleagues reported on a 37-year-old woman presenting with perineal and right lower-extremity radicular pain. ${ }^{11}$ She was found to have 3 concurrent spinal perimedullary fistulas, which were treated with both embolization (of a large varix with platinum coil/NBCA mixture) and surgery (coagulation of multiple small AVFs and varix excision). Sharma published a case of a 16 -year-old boy presenting with bilateral lower-extremity weakness and back pain..$^{12}$ This patient was found to have multifocal intradural spinal AVFs and bilateral renal artery aneurysms. The treatment was not described in this case. Tokunaga and colleagues presented a case of a 7-year-old girl with multiple perimedullary AVFs, which were treated successfully using a combination of transarterial and transvenous embolization. ${ }^{14}$ Finally, Iizuka and colleagues described the case of a 24-year-old woman with a conus medullaris spinal AVM who presented twice with SAH. ${ }^{4}$ She underwent transarterial glue embolization.
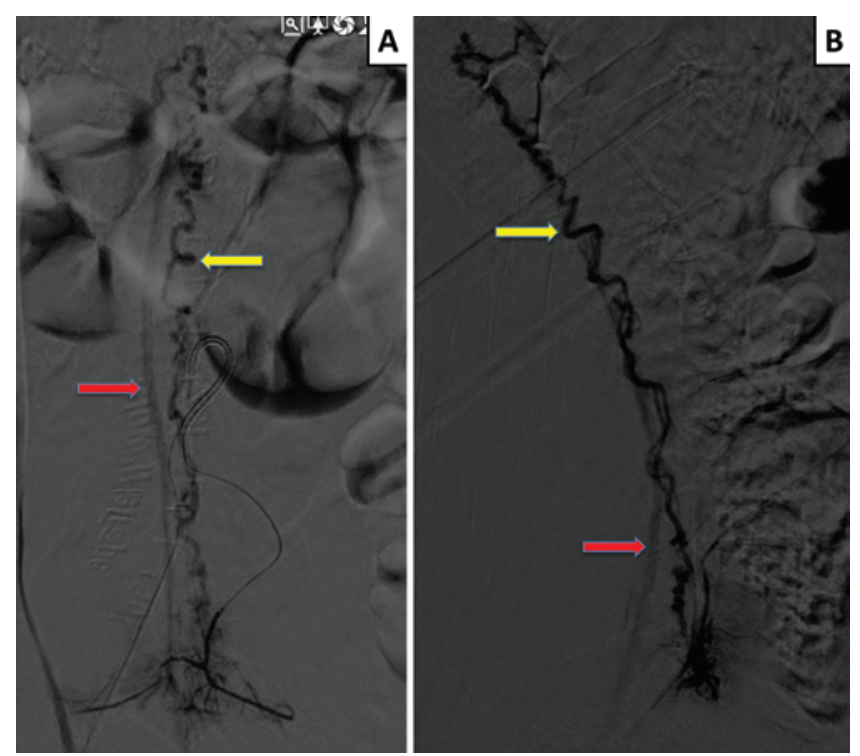

FIG. 4. Anteroposterior (A) and lateral (B) DSA studies of the left L-4 lumbar artery, demonstrating a radiculomedullary fistula with an ascending intradural dorsal serpiginous dilated vein (yellow arrows) up to the conus medullaris that further drains into the arterialized extradural vein (red arrows). Figure is available in color online only.

\section{Differential Diagnostic Considerations}

KTS and PWS are similar limb-overgrowth disorders characterized by complex vascular anomalies. These conditions have frequently been grouped together in the medical literature under the misnomer Klippel-TrenaunayWeber syndrome, despite important differences. Since KTS and PWS are distinct entities, the grouping together of these conditions using the name Klippel-TrenaunayWeber syndrome should be strongly discouraged.

Significant AV shunting/high-flow vascular malformations characterize PWS, whereas KTS is strictly a condition consisting of slow-flow malformations (including lymphatic, capillary, and venous vascular anomalies).,18 Conflating the two syndromes fails to recognize vascular biological and genetic differences. Differentiating between KTS and PWS is essential, since they differ markedly in their clinical manifestations and unique treatment approaches. ${ }^{6,8}$

Though PWS was initially thought to be a sporadic disorder, genetic links have been found to a mutation in RASA1. This may also be seen in other fast-flow vascular anomalies, including capillary malformation-AVMs and vein of Galen aneurysmal malformations. This mutation helps distinguish PWS from other overgrowth disorders such as hereditary hemorrhagic telangiectasia with highflow AVFs, PTEN hamartomatous tumor syndrome, and KTS. ${ }^{6,9,10}$ This gene mutation similarly has been associated with spinal AV anomalies in patients with multifocal capillary malformations. ${ }^{13}$ Thus, genetic testing may be helpful to ensure the correct diagnosis in certain patients if it remains unclear clinically and can thereby help direct management and prompt further investigation for spinal vascular malformations. Genetic testing was not performed in our patient because of the inability by the parents to afford 

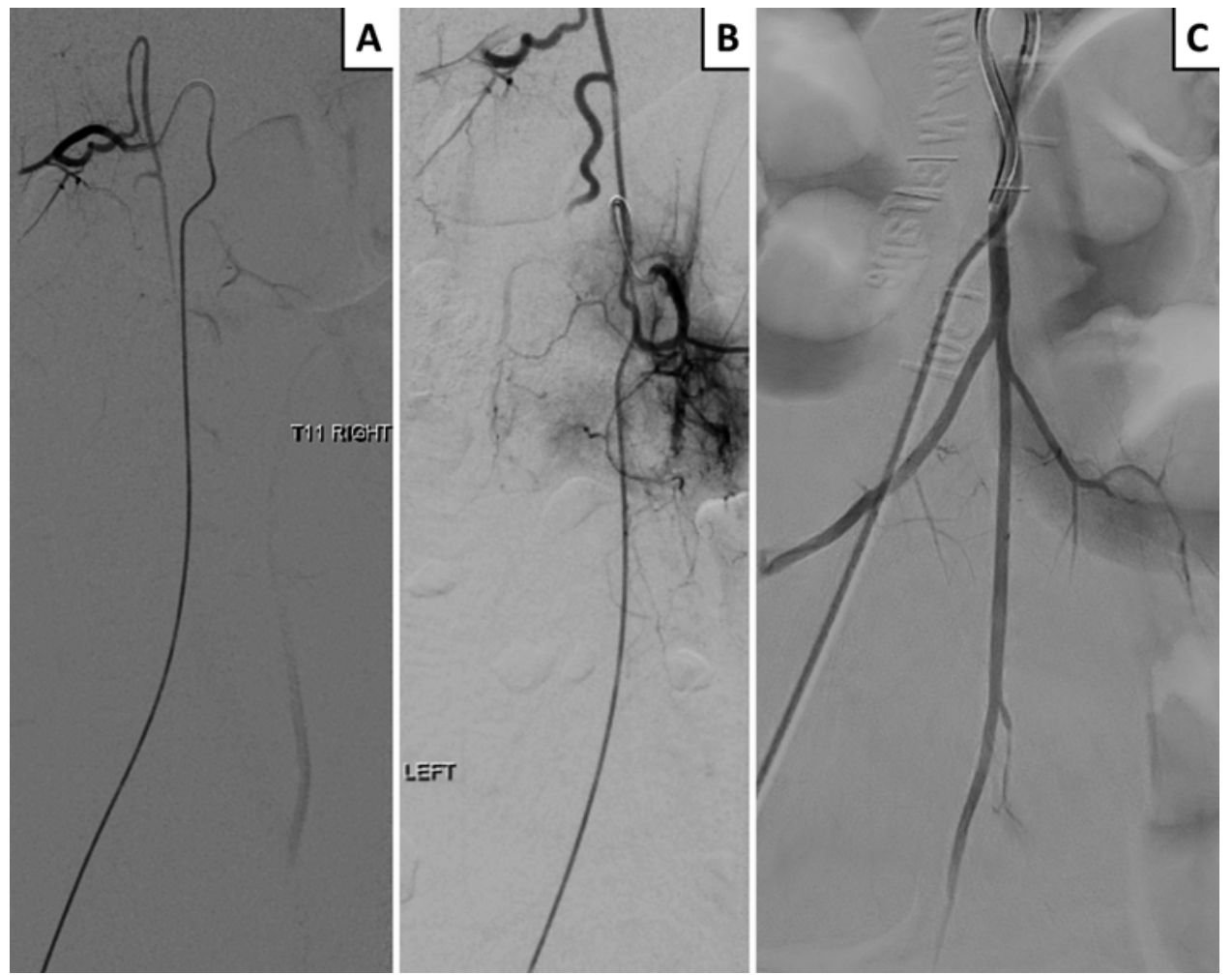

FIG. 5. After superselective embolization with NBCA, DSA studies of the right T-11 intercostal artery (A), left L-1 lumbar artery (B), and left L-4 lumbar artery (C) showed complete obliteration of the fistulas without opacification of the pseudonidus centered at the conus medullaris.

the cost. However, we did not feel it was necessary as our diagnosis was straightforward.

\section{Workup and Treatment Considerations}

The yield of spinal axis imaging in nonaneurysmal $\mathrm{SAH}$ is low, particularly in perimesencephalic SAH. ${ }^{3}$ However, imaging of the spine should be considered in certain patients. At our institution, we perform MRI of the spine particularly when cerebral digital subtraction angiography (DSA) is nonrevealing (especially after 2 or more consecutive negative cerebral DSA studies) and in the following cases: posterior fossa-predominant $\mathrm{SAH}$, certain predisposing vascular disorders, and pediatric patients because AVMs are more commonly a source of SAH when compared with the adult population.

When evaluating spinal vascular malformations in PWS, angiographic assessment should be thorough, as these lesions usually contain multiple fistulas. Endovascular angiography necessitates the evaluation of multiple visceral arteries to identify all potential "feeders" to the fistula. Careful assessment allows for precise classification of the lesions; this is essential to identify both the anterior and posterior spinal arteries and for treatment planning.

The classification of spinal AVMs and AVFs has evolved and has been under constant revision. The modified classification system proposed by Kim and Spetzler is based on anatomical and pathophysiological features of these lesions. Our patient had both intradural ventral and dorsal fistulas with large dilated veins within the conus medullaris, compatible with the complex angioarchitecture of a conus medullaris AVM in their classification. ${ }^{5}$

If left untreated, these patients often experience progressive neurological decline or recurring acute hemorrhagic events, including spinal cord hematoma and SAH. Although there are no consensus guidelines for the treatment of intraspinal AVFs in patients with PWS, treatment should be individualized based on the angioarchitecture of the lesion and treatment goals set for the patient. Complete obliteration of the lesion may be challenging, and treatment should focus on clinical improvement and reducing the volume of the malformation.

Wilson and colleagues have demonstrated excellent long-term outcomes using combined endovascular and microsurgical treatments of conus medullaris AVMs, with $86 \%$ of patients remaining neurologically stable or improving over the long term. ${ }^{17}$ Similarly, a multimodality approach resulted in a positive outcome in our patient without complications.

The treatment for our patient was thoroughly discussed among the neurosurgery, neurointervention, and neurology services. It was deemed that the presence of multiple arterial feeders conveying to a pseudonidal point at the level of the conus medullaris was more amenable to a surgical ligation, particularly the posterior arterial feeders, rather than multiple embolizations through the arterial side. It was thought the surgical ligation would offer a more durable solution without the need of exposing the 
young girl to repetitive endovascular treatments and the stochastic risks of excess radiation.

\section{References}

1. Baskerville PA, Ackroyd JS, Lea Thomas M, Browse NL: The Klippel-Trenaunay syndrome: clinical, radiological and haemodynamic features and management. Br J Surg 72:232-236, 1985

2. Courivaud D, Delerue A, Delerue C, Boon L, Piette F, Modiano P: [Familial case of Parkes Weber syndrome.] Ann Dermatol Venereol 133:445-447, 2006 (Fr)

3. Germans MR, Coert BA, Majoie CB, van den Berg R, Verbaan D, Vandertop WP: Spinal axis imaging in non-aneurysmal subarachnoid hemorrhage: a prospective cohort study. J Neurol 261:2199-2203, 2014

4. Iizuka Y, Suzuki M, Komura S, Takada T, Shimoji K: Conus medullaris spinal arteriovenous malformation in a patient with Klippel-Trenaunay-Weber syndrome. A case report and review of the literature. Interv Neuroradiol 14:185-190, 2008

5. Kim LJ, Spetzler RF: Classification and surgical management of spinal arteriovenous lesions: arteriovenous fistulae and arteriovenous malformations. Neurosurgery $59(5$ Suppl 3):S195-S201, S3-S13, 2006

6. Lobo-Mueller E, Amaral JG, Babyn PS, Wang Q, John P: Complex combined vascular malformations and vascular malformation syndromes affecting the extremities in children. Semin Musculoskelet Radiol 13:255-276, 2009

7. Nakstad PH, Hald JK, Bakke SJ: Multiple spinal arteriovenous fistulas in Klippel-Trenaunay-Weber syndrome treated with platinum fibre coils. Neuroradiology 35:163-165, 1993

8. Oduber CE, van der Horst CM, Hennekam RC: KlippelTrenaunay syndrome: diagnostic criteria and hypothesis on etiology. Ann Plast Surg 60:217-223, 2008

9. Revencu N, Boon LM, Dompmartin A, Rieu P, Busch WL, Dubois J, et al: Germline mutations in RASA1 are not found in patients with Klippel-Trenaunay syndrome or capillary malformation with limb overgrowth. Mol Syndromol 4:173178,2013

10. Revencu N, Boon LM, Mulliken JB, Enjolras O, Cordisco MR, Burrows PE, et al: Parkes Weber syndrome, vein of Galen aneurysmal malformation, and other fast-flow vascular anomalies are caused by RASA1 mutations. Hum Mutat 29:959-965, 2008

11. Rohany M, Shaibani A, Arafat O, Walker MT, Russell EJ, Batjer HH, et al: Spinal arteriovenous malformations associated with Klippel-Trenaunay-Weber syndrome: a literature search and report of two cases. AJNR Am J Neuroradiol 28:584-589, 2007
12. Sharma S: Multifocal intradural spinal AVF and renal artery aneurysms in a case of Klippel Trenaunay syndrome (KTS). J Neuroimaging 20:386-389, 2010

13. Thiex R, Mulliken JB, Revencu N, Boon LM, Burrows PE, Cordisco M, et al: A novel association between RASA1 mutations and spinal arteriovenous anomalies. AJNR Am J Neuroradiol 31:775-779, 2010

14. Tokunaga K, Hishikawa T, Sugiu K, Date I: Combined transarterial and transvenous approach for curative obliteration of Klippel-Trenaunay-Weber syndrome-associated spinal perimedullary arteriovenous fistulas. Clin Neuroradiol 25:291-294, 2015

15. Wassef M, Blei F, Adams D, Alomari A, Baselga E, Berenstein A, et al: Vascular anomalies classification: recommendations from the International Society for the Study of Vascular Anomalies. Pediatrics 136:e203-e214, 2015

16. Weber FP: Angioma-formation in connection with hypertrophy of the limbs and hemihypertrophy. Br J Dermatol 19:231-235, 1907

17. Wilson DA, Abla AA, Uschold TD, McDougall CG, Albuquerque FC, Spetzler RF: Multimodality treatment of conus medullaris arteriovenous malformations: 2 decades of experience with combined endovascular and microsurgical treatments. Neurosurgery 71:100-108, 2012

18. Ziyeh S, Spreer J, Rössler J, Strecker R, Hochmuth A, Schumacher M, et al: Parkes Weber or Klippel-Trenaunay syndrome? Non-invasive diagnosis with MR projection angiography. Eur Radiol 14:2025-2029, 2004

\section{Disclosures}

The authors report no conflict of interest concerning the materials or methods used in this study or the findings specified in this paper.

\section{Author Contributions}

Conception and design: Bagherpour, Rodriguez, Moorthy, Maud. Drafting the article: Bagherpour, Maud. Critically revising the article: all authors. Reviewed submitted version of manuscript: all authors. Approved the final version of the manuscript on behalf of all authors: Bagherpour. Administrative/technical/material support: Bagherpour, Rodriguez, Maud. Study supervision: Maud.

\section{Correspondence}

Arya N. Bagherpour, Department of Radiology, Texas Tech University Health Sciences Center, 5001 El Paso Dr., El Paso, TX 79905.email: arya.bagherpour@ttuhsc.edu. 